\title{
Settlement simulation of soft clay in the subway under dynamic load based on Midas GTS NX
}

\author{
Quan $\mathrm{Cao}^{1}$, Yu Hang ${ }^{1, *}$ \\ ${ }^{1}$ School of Railway Transportation, Shanghai Institute of Technology, Shanghai 201418, China
}

\begin{abstract}
The subway has become the main way for people to travel nowadays. The saturated soft clay area has a large population and subway construction is the most extensively distributed. The saturated soft clay foundation will settle under the dynamic load of the subway train, which will affect the service life and structural safety. To study the settlement characteristics of soft clay under the dynamic load of the subway, a three-dimensional dynamic finite element model was established based on the finite element software Midas GTS NX, and the soft clay under the normal design speed $(80 \mathrm{~km} / \mathrm{h})$ and the high-speed $(120 \mathrm{~km} / \mathrm{h})$ were compared and analyzed. The research results show that the higher the train speed, the larger the lateral influence range of the surface settlement trough, but the settlement decreases with the increase of the subway running speed. The settlement of the subway line after one year of operation is about $45 \mathrm{~mm}$, and the settlement after 20 years is about $58 \mathrm{~mm}$. The growth rate of the settlement prediction curve decreases gradually, and the settlement increment is very small for a long time in the later period of operation.
\end{abstract}

\section{Introduction}

The construction of the subway has a significant effect on improving the utilization rate of urban land and alleviating the increasingly crowded urban traffic. Cities in the saturated soft clay area (take Shanghai as an example) have a large population, and the subway has gradually become the main way for people to travel. With the popularization of subway trains, a series of engineering problems have also caused. When the soft soil foundation is subjected to continuous dynamic load, even the soft soil foundation after a long-term consolidation process will produce different degrees of settlement. Once the saturated soft clay layer has a large settlement, the tunnel structure will suffer from water leakage, mud leakage, and pipe segment fracture, which will seriously affect the normal operation safety and efficiency of the subway. Under the action of long-term cyclic load, the soft soil foundation will produce a post-construction settlement, which will affect the performance and service life of the subgrade. Shanghai Metro Line 1 put into operation in 1995, the settlement problem is more serious, the settlement reached $6 \mathrm{~cm}$ after 8 months of opening to traffic, and the settlement of several sections is still showing a developing trend, with the maximum annual settlement value reaching $40 \mathrm{~mm}$ [1].

At present, the commonly used research methods for soil settlement under subway dynamic loads include theoretical calculation methods, empirical methods combined with field measurements, indoor model test methods, and numerical simulation methods. Shirlaw [2] studied the long-term settlement data of a lot of tunnels and found that the long-term settlement of soft soil tunnels can usually account for more than $30 \%$ of the total settlement. Yan Chunling and Tang Yiqun [3] reviewed the dynamic characteristics of silty soil under the subway load and the long-term subsidence of subway tunnels. They found that the subway tunnels will be subjected to intermittent cyclical loads after they are completed and put into operation. Fujiwara et al. [4-5] comprehensively discussed the effects of total load, load cycle, load increment ratio, loading method, cementation degree, and cycle times on clay deformation, and found that the consolidation deformation under cyclic load was greater than that under static load. Ding Zhi et al. [6], Liu Ming et al. [7], Yildirim A et al. [8], Yilmaz et al. [9], and $\mathrm{He}$ Shaoheng et al. [10] also conducted related studies on the settlement of soft soils under subway dynamic load.

Midas GTS NX is a finite element software developed for geotechnical engineering. The software has powerful pre-processing and post-processing modes that can meet most engineering needs. In this article, Midas GTS NX is used to establish a three-dimensional finite element calculation model for the interaction between train lining, roadbed, and soil to simulate subway vibration, and analyze the settlement variation law of soft soil foundation under the normal design speed $(80 \mathrm{~km} / \mathrm{h})$ and high speed $(120 \mathrm{~km} / \mathrm{h})$ of subway trains. Based on the simulation study of the influence of subway vibration on the strata along the line and the subsidence of the strata, the article predicts the settlement of the ground during operation by

* Corresponding author: sakuragihy@163.com 
combining the theoretical and empirical formula, which provides a reference for the design and long-term service safety evaluation of subway engineering in soft soil area.

\section{Geological conditions}

The soil of this model was selected in the section from Fanghua Road Station to Longyang Road Station on Shanghai Metro Line 7, and the typical geological section was selected as the soft clay settlement simulation object. The soil in the $30 \mathrm{~m}$ depth range of the survey borehole is mostly soft clay, and there are 7 soil layers in the exploration depth. The typical interval geological crosssection is shown in Fig. 1. The buried depth of the tunnel is $15 \mathrm{~m}$.

The survey samples were subjected to indoor geotechnical tests and statistical analysis of the results. The physical and mechanical indexes of each soil layer were shown in Table 1.

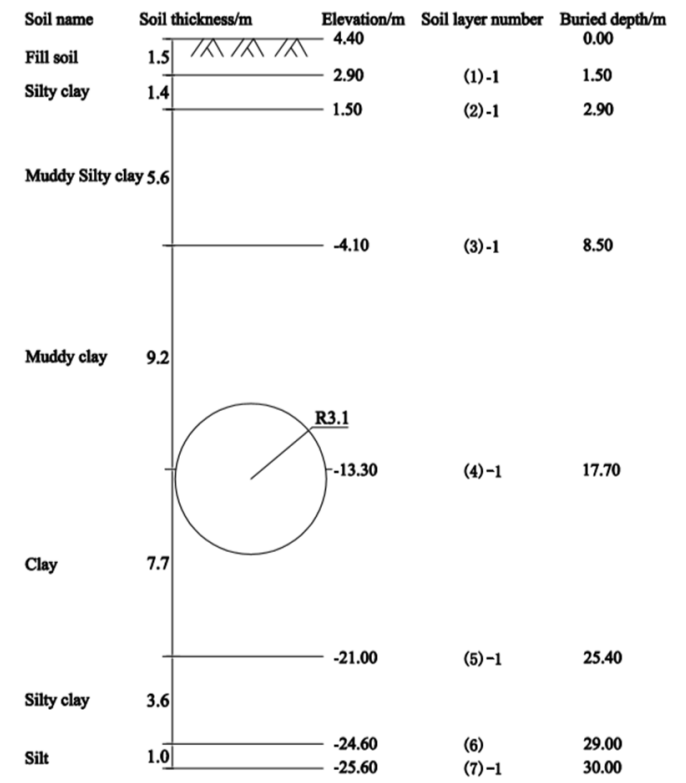

Fig1. Typical interval geological section

Table1. Physical and mechanical parameters of soil layers

\begin{tabular}{|c|c|c|c|c|c|}
\hline \multirow{2}{*}{$\begin{array}{c}\text { Soil } \\
\text { name }\end{array}$} & \multirow{2}{*}{$\begin{array}{c}\text { Bulk } \\
\text { density } \\
\gamma / \\
\mathrm{kN} / \mathrm{m}^{3}\end{array}$} & \multirow{2}{*}{$\begin{array}{c}\text { Poisson's } \\
\text { ratio } \\
v\end{array}$} & \multirow{2}{*}{$\begin{array}{l}E_{\mathrm{s} 0.1-0.2} \\
/ \mathrm{MPa}\end{array}$} & \multicolumn{2}{|c|}{$\mathrm{CU}$} \\
\hline & & & & $\begin{array}{l}C_{\mathrm{CU}} \\
/ \mathrm{kPa}\end{array}$ & $\begin{array}{l}\varphi_{\mathrm{CU}} \\
/\left(^{\circ}\right)\end{array}$ \\
\hline Silty clay & 18.8 & 0.35 & 5.64 & 21.0 & 23.0 \\
\hline $\begin{array}{c}\text { Muddy } \\
\text { Silty clay }\end{array}$ & 17.4 & 0.25 & 3.22 & 12.5 & 17.3 \\
\hline $\begin{array}{l}\text { Muddy } \\
\text { clay }\end{array}$ & 16.7 & 0.25 & 2.32 & 14.0 & 11.8 \\
\hline Clay & 17.4 & 0.35 & 3.02 & 16.0 & 13.8 \\
\hline Silty clay & 19.2 & 0.35 & 6.55 & 48.0 & 17.0 \\
\hline Silt & 18.6 & 0.25 & 12.49 & 2.0 & 32.5 \\
\hline Silt & 18.6 & 0.25 & 13.03 & 0.5 & 33.5 \\
\hline
\end{tabular}

\section{Numerical simulation}

The outer diameter of the shield tunnel of the subway line is $6.2 \mathrm{~m}$, the inner diameter is $5.5 \mathrm{~m}$, the segment thickness is $350 \mathrm{~mm}$, the trackbed thickness is $0.450 \mathrm{~m}$, the standard gauge is $1.435 \mathrm{~m}$, and the strength grade of the precast concrete lining segment is C55. Midas GTS NX was used to establish a soil model, according to the characteristics of finite element simulation and considering the actual force situation and boundary effect of the subway station, the model can be simplified appropriately. The upper layer including the fill layer is merged into a silty clay layer, the middle layer is merged into a clay layer, which contains the subway tunnel, and the lower part is a silty layer. When establishing soil parameters, the soil layer with weaker elastic modulus is taken as the most unfavorable situation, and the established model is safer and more reliable. The model size is $62 \mathrm{~m} \times 50 \mathrm{~m} \times 120 \mathrm{~m}$, as shown in Fig. 2. The tunnel structure model of the lining and trackbed is shown in Fig. 3.

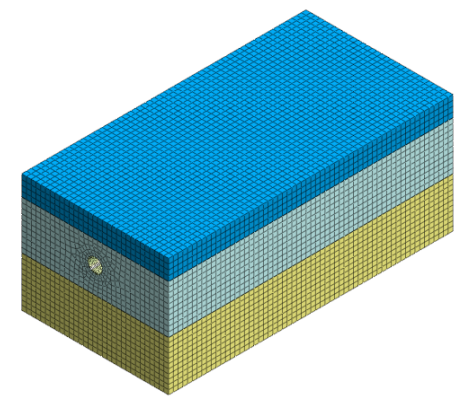

Fig2. Soil model

Soil parameters of typical sections completed by laboratory tests were extracted, physical and mechanical parameters of soil layers were shown in Table 1. The model range of numerical simulation is as follows: take 10 times the outside diameter of the tunnel in the horizontal $\mathrm{X}$ direction, that is $62 \mathrm{~m}$, take $120 \mathrm{~m}$ in the vertical $\mathrm{Y}$ direction, and take $50 \mathrm{~m}$ in the longitudinal $\mathrm{Z}$ direction. The five loads of train dynamic load were calculated, and each load was recorded and analyzed respectively.

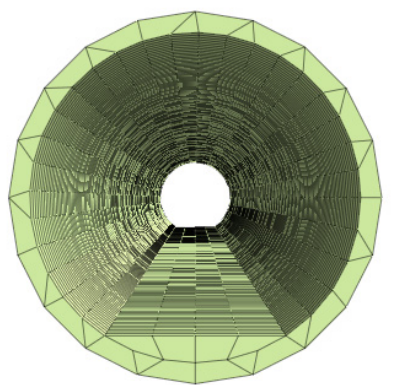

Fig3. Tunnel structural model

Eigenvalue analysis is used to analyze the dynamic characteristics of the structure itself, and is also called "free vibration analysis". The periods of the first and second main modes of the eigenvalue analysis will be used in the time history analysis to calculate the damping matrix. We select all meshes to establish an elastic boundary with ground springs, select "Eigenvalue" as the solution type, activate all meshes and elastic boundary conditions, and check the eigenvalue analysis result table. The periods of the first and second main modes should be focused on. 
In static analysis, it is necessary to ensure that the boundary is sufficiently far away from the main area for models containing infinite materials such as rock and soil. But in the dynamic analysis, the wave will be reflected. If the boundary setting is the same as the static analysis, it is likely to be wrong. To avoid errors, we use approximate methods, such as artificial boundary, transitive boundary or hyperfinite element, infinite element, and boundary element. This article adopting a "sticky boundary".

The train dynamic load is applied to the model. The moving train dynamic load is used to simulate the operation of the subway train. Select the node where the subway load is applied (the wheel passing point). Select the starting and ending nodes according to the direction of the subway and enter the proposed train speed. Select "linear time history (direct integration method)" to solve. Enter the results of the previous eigenvalue analysis, and drag all meshes, viscous conditions, and dynamic loads to the activation group to start the calculation.

\section{Analysis of calculation results}

\subsection{Vertical settlement of the soil at the bottom of the tunnel}

In this settlement simulation, we calculated the case where the vehicle dynamic load was cyclically loaded five times at two different speeds of $80 \mathrm{~km} / \mathrm{h}$ and $120 \mathrm{~km} / \mathrm{h}$. The soil settlement is shown in Fig. 4-Fig. 6. It can be seen from the comparison of the figures that as the depth increases, the vertical cumulative settlement of the soil gradually decreases. For the average settlement value of the soil at the same depth, the settlement at the normal speed is greater than that at the faster speed. The trainload frequency is relatively low. The lower the frequency, the slower the load change, and the longer the load action time, which is more conducive to the compaction of the soil. The more energy acts on the soil, the lower the frequency, the greater the accumulated strain of the soil will be generated, thus resulting in greater deformation of the soil.

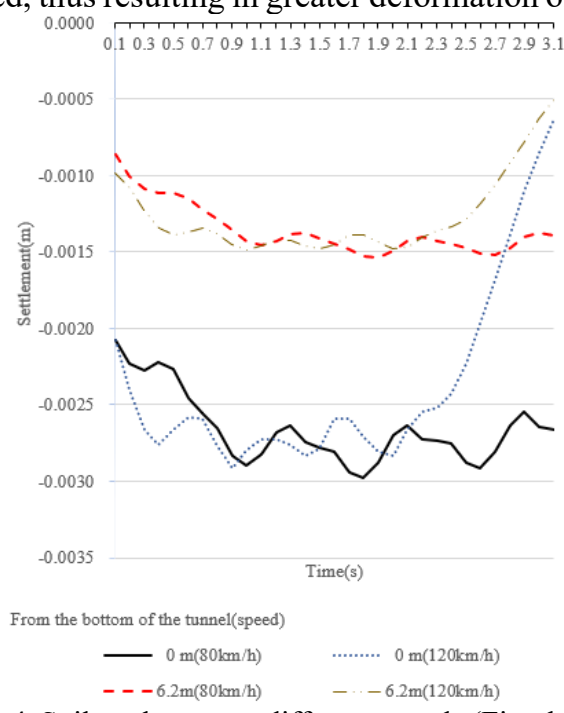

Fig4. Soil settlement at different speeds (First load)

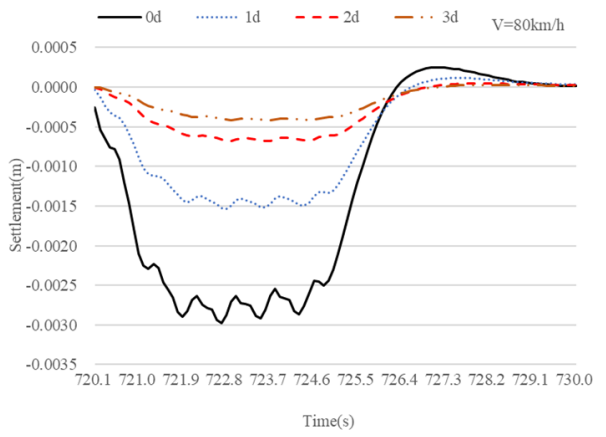

Fig5. Settlements at bottom of tunnel (5th time)

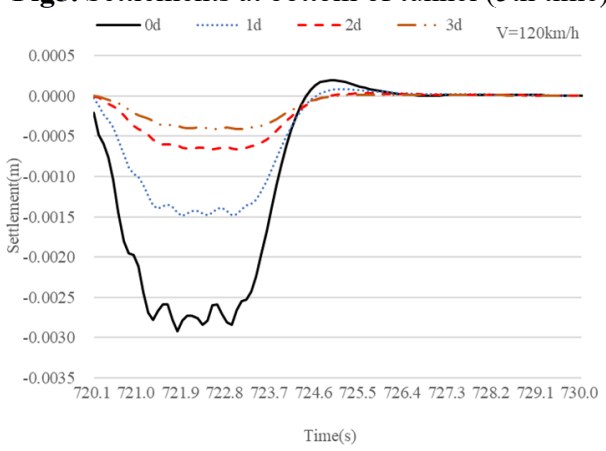

Fig6. High-speed settlements at bottom of tunnel (5th time)

\subsection{Vertical settlement of lateral soil}

Fig. 7 shows the vertical settlement curve of the soil in the surface horizontal settlement trough at different speeds. It can be seen from the figure that the surface settlement trough under normal speed is more obvious, the center depth of the settlement trough is greater than the faster speed, and the settlement decreases as the distance from the tunnel axis increases. When the train increases to a faster speed, the lateral influence range of the settlement trough gradually develops from "deep and narrow" to "shallow and wide".

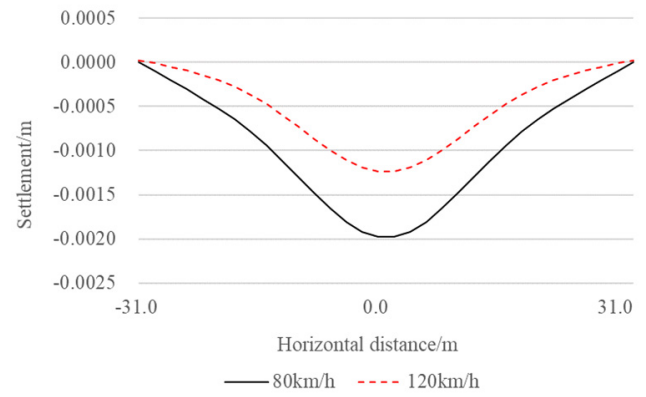

Fig7. Horizontal settlements of the ground surface

\section{Settlement prediction}

Based on the numerical simulation results and empirical prediction formulas, in this article we propose an empirical prediction model of construction settlement during operation time:

$$
\begin{aligned}
& s=\gamma \sum_{i}^{n} \varepsilon h_{i} \\
& \varepsilon=0.96 N^{0.085}
\end{aligned}
$$

Where $\varepsilon$ is the cumulative plastic strain of the calculated soil layer, $\mathrm{N}$ is the number of vibrations, $S$ is the 
predicted settlement value $(\mathrm{mm}), \gamma$ is the correction coefficient considering experience, generally can be 0.85 . $h_{i}$ is the thickness of the calculated soil layer, generally can be considered 3 to 4 times the tunnel diameter lying depth, or maximum $20 \mathrm{~m}$. According to the proposed settlement prediction empirical model, the settlement prediction during the post-construction operation period is carried out. The number of vibrations per year is calculated as 400 thousand times. Fig. 8 shows the settlement evolution curve of this line from the beginning of the operation to 20 years of operation. It can be seen from the figure that the settlement prediction value in the first year is $45 \mathrm{~mm}$, and the settlement prediction value in the 20 -year operation period has reached $58 \mathrm{~mm}$. The growth rate of the settlement prediction curve gradually decreases, and finally, tends to zero. In the later period of operation, the settlement increment is very small in a long time increment.

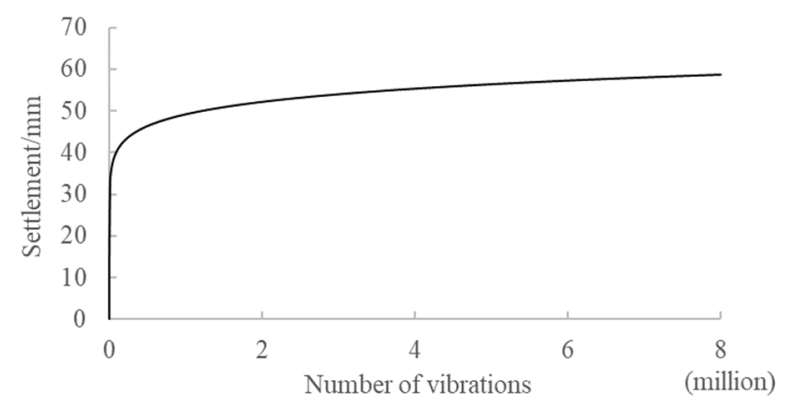

Fig8. 20 years development curve of predicted tunnel settlement

\section{Conclusion}

This article discusses the settlement characteristics of soft clay under the dynamic load of the subway at a different speed, analyzes the cumulative plastic deformation of typical soil layer under the dynamic load. The settlement prediction model of the shield tunnel was established, and the post-construction settlement of the soft ground under the tunnel was predicted and analyzed. The main conclusions are as follows:

(1) For the vertical settlement value of soil at the same depth, the settlement at the normal speed is larger than the faster speed. Under the normal speed, the strain response of the soil under the tunnel is more obvious, and the settlement curve is relatively "high and steep". Compared with the normal speed, the post-construction operation settlement caused by the faster subway train is smaller.

(2) When the train increases from normal speed to the faster speed, the lateral influence range of the settlement trough gradually develops from "deep and narrow" to "shallow and wide". The lateral influence range of the surface settlement trough is larger, but its maximum settlement value is relatively reduced.

(3) Under the action of the subway dynamic load, the long-term settlement development of the tunnel conforms to the exponential growth law. As the operating time increases, the influence of the trainload on the settlement of the soft soil around the tunnel gradually tends to be stable. The settlement in one year after the operation is about $45 \mathrm{~mm}$ and is predicted to be up to $58 \mathrm{~mm}$ in 20 years of operation, which provides a reference for engineering decision-making.

\section{Acknowledgements}

The author thanks the financial support from School of Railway Transportation, Shanghai Institute of Technology.

\section{References}

1. Y.D. Ye, H.H. Zhu, R.L. Wang. The present situation and cause analysis of the diseases of the railway operating tunnel in soft soil. Journal of Underground Space and Engineering, 3(1): 157-160 (2007)

2. J.N. Shirlaw. Observed and calculated pore pressures and deformations induced by an earth balance shield. Canadian Geotechnical Journal, 32(30): 476-490 (2011)

3. C.L. Yan, Y.Q. Tang. Research progress of dynamic characteristics of silt soil under the subway load. Journal of Earthquake Engineering, 33(2): 200-205 (2011)

4. H. Fujiwara, T. Yamanuochi, K. Yasuhara. Consolidation of alluvial clay under repeated loading. Soils and Foundations, 25(3): 19-30 (1985)

5. H. Fujiwara, U. Shunji, Y. Kazuya. Secondary compression of clay under repeated loading. Soils and Foundations, 27(2): 21-30 (1987)

6. Z. Ding, J.L. Fan, M.Y. Zhang. Model test study on undisturbed soil pore pressure and strain under the subway trainload. Journal of the China Railway Society, 39(3): 96-103 (2017)

7. M. Liu, M.S. Huang, Y.H. Liu. Analysis of long-term settlement of cross-river tunnel in soft soil caused by vehicle vibration. Chinese Journal of Geotechnical Engineering, 31(11): 1703-1709 (2009)

8. A. Yildirim, H. Ersan. Settlements under consecutive series of cyclic loading. Soil Dynamics and Earthquake Engineering, 27(6): 577-585 (2007)

9. M.T. Yilmaz, O. Pekcan, B.S. Bakir. Undrained cyclic shear and deformation behavior of silt clay mixtures of Adapazari in Turkey. Soil Dynamics and Earthquake Engineering, 24(7): 497-507 (2004)

10. S.H. He, Q.Q. Zheng, T.D. Xia. Experimental study on long-term dynamic characteristics of marine soft soil under subway train load considering time intermittent effect. Chinese Journal of Rock Mechanics and Engineering, 1-11 (2018) 